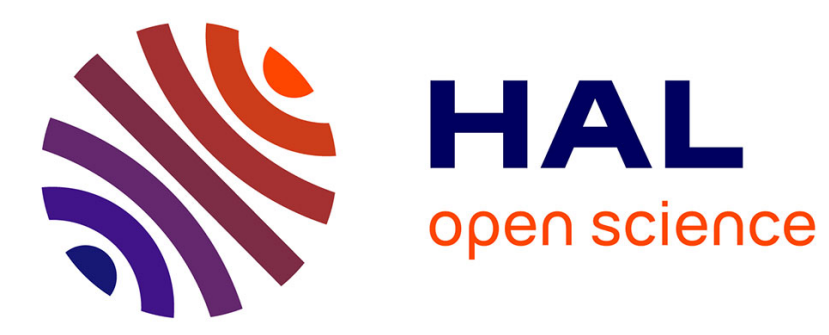

\title{
Mechanical and electrical properties of polymer-derived Si-C-N ceramics reinforced by octadecylamine - modified single-wall carbon nanotubes
}

D. Shopova-Gospodinova, Z. Burghard, T. Dufaux, M. Burghard, J. Bill

\section{- To cite this version:}

D. Shopova-Gospodinova, Z. Burghard, T. Dufaux, M. Burghard, J. Bill. Mechanical and electrical properties of polymer-derived Si-C-N ceramics reinforced by octadecylamine - modified single-wall carbon nanotubes. Composites Science and Technology, 2011, 71 (6), pp.931. 10.1016/j.compscitech.2011.02.013 . hal-00736299

\section{HAL Id: hal-00736299 \\ https://hal.science/hal-00736299}

Submitted on 28 Sep 2012

HAL is a multi-disciplinary open access archive for the deposit and dissemination of scientific research documents, whether they are published or not. The documents may come from teaching and research institutions in France or abroad, or from public or private research centers.
L'archive ouverte pluridisciplinaire HAL, est destinée au dépôt et à la diffusion de documents scientifiques de niveau recherche, publiés ou non, émanant des établissements d'enseignement et de recherche français ou étrangers, des laboratoires publics ou privés. 


\section{Accepted Manuscript}

Mechanical and electrical properties of polymer-derived Si-C-N ceramics reinforced by octadecylamine - modified single-wall carbon nanotubes

D. Shopova-Gospodinova, Z. Burghard, T. Dufaux, M. Burghard, J. Bill

PII: S0266-3538(11)00089-3

DOI: 10.1016/j.compscitech.2011.02.013

Reference: CSTE 4938

To appear in: Composites Science and Technology

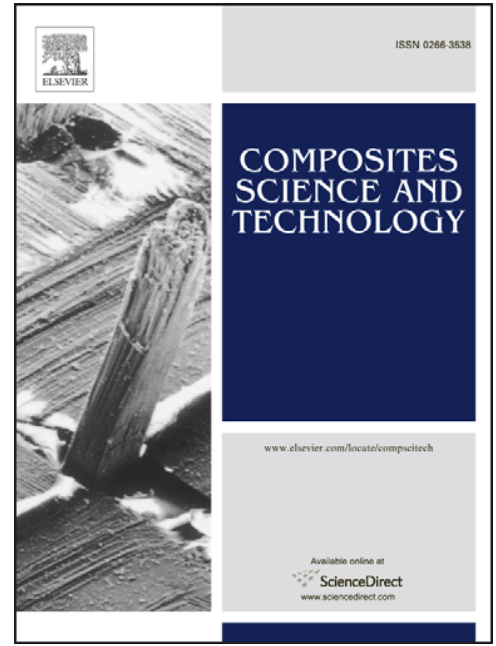

Received Date: $\quad 11$ November 2010

Revised Date: $\quad 21$ February 2011

Accepted Date: $\quad 24$ February 2011

Please cite this article as: Shopova-Gospodinova, D., Burghard, Z., Dufaux, T., Burghard, M., Bill, J., Mechanical and electrical properties of polymer-derived Si-C-N ceramics reinforced by octadecylamine - modified single-wall carbon nanotubes, Composites Science and Technology(2011), doi: 10.1016/j.compscitech.2011.02.013

This is a PDF file of an unedited manuscript that has been accepted for publication. As a service to our customers we are providing this early version of the manuscript. The manuscript will undergo copyediting, typesetting, and review of the resulting proof before it is published in its final form. Please note that during the production process errors may be discovered which could affect the content, and all legal disclaimers that apply to the journal pertain. 


\section{Mechanical and electrical properties of polymer-derived Si-C-N ceramics reinforced by octadecylamine - modified single-wall carbon nanotubes}

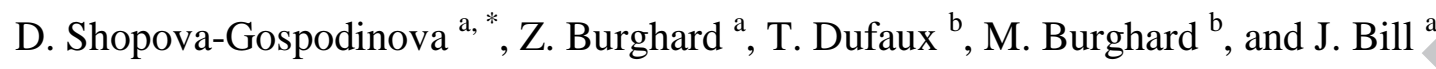

[ $\left.{ }^{\mathrm{a}}\right] \quad$ Dr. D. Shopova-Gospodinova, Dr. Z. Burghard, Prof. J. Bill

Institut für Materialwissenschaft, Universität Stuttgart, Heisenbergstraße 3, 70569 Stuttgart, Germany

[b] T. Dufaux, PD Dr. M. Burghard

Max-Planck-Institut für Festkörperforschung, Heisenbergstrasse 1,

70569 Stuttgart, Germany

*Corresponding author. Tel: 0049711 685-61967 Fax: 0049 711 689-1010

E-mail: mwishopova@imw.uni-stuttgart.de

Dedicated to Professor Wolfgang Laqua on the Occasion of his $75^{\text {th }}$ Birthday

Polymer-derived Si-C-N ceramics reinforced by homogeneously distributed octadecylaminefunctionalized single-walled carbon nanotubes (SWCNTs) were synthesized using a casting process, successive pressureless cross-linking and thermolysis. We find that the incorporation of even small amounts of modified SWCNTs leads to a remarkable improvement of mechanical and electrical transport properties of our composites. In particular, we find twofold enhancement of fracture toughness. The Youngs modulus and the hardness show increase by $\sim 30$ and $15 \%$, respectively. Furthermore, the electrical conductivity was found to increase more than five orders of magnitude even for a tube content of $0.5 \mathrm{wt} \%$.

Keywords: A. carbon nanotubes, A. polymer-matrix composites, B. mechanical properties, B. electrical properties 


\section{Introduction}

Ceramics based upon polymer-derived silicon carbonitride ( $\mathrm{Si}-\mathrm{C}-\mathrm{N})$ have attracted great interest for structural applications due to their low density, high hardness and elastic modulus, extraordinary chemical stability, and high creep resistance at elevated temperatures [1-5]. These excellent properties are reached through cross-linking and pyrolysis of organosilicon precursor polymers, leading to ceramics with high purity, controlled structure and chemical composition $[1,6,7]$. Depending on the chemical nature of the starting precursor and pyrolysis conditions, different ceramics whose atomic structure ranges from fully amorphous to nanocrystalline can be obtained [8]. Moreover, this synthesis route enables forming ceramics bodies into small scales and complex shapes, which is of strong relevance for many technological applications. However, like all ceramics, the resulting non-oxide material suffers from low fracture resistance and poor electrical conductivity [9-11]. Consequently, strategies to improve the fracture resistance and electrical conductivity of these materials are needed in order fully exploit their application perspectives.

Enhanced fracture resistance of ceramic materials has been achieved, among other approaches, via tailoring the microstructure by incorporating a second phase in the form of particles or fibres. Carbon nanotubes (CNTs) have proven particularly useful for this purpose [12, 13], owing to their extraordinary mechanical [14-17], thermal [18] and electrical properties [19], as well as their low weight and high aspect ratio. There are numerous examples of enhanced electrical conductivity upon incorporation of carbon nanotubes in polymer matrices [20]. For instance, Ionescu et al. have attained good electrical conductivity through incorporation of 5 vol\% multi-wall carbon nanotubes (MWCNT) into polysilazane-derived SiCN ceramic.

Up to date, several mechanical studies of CNTs/polymer-derived ceramic composites have been reported, in most cases comprising multi-wall carbon nanotubes (MWCNTs) as reinforcing elements $[21,22]$. In one case, the MWCNTs were mixed into a Si-C-N ceramic 
precursor solution, followed by catalytic cross-linking and pressure-assisted pyrolysis at $1000^{\circ} \mathrm{C}$ [21]. In this manner, a substantial increase in Young's modulus, hardness and contact-damage resistance was achieved for a MWCNTs content of $\sim 6 \mathrm{vol} \%$. In a related work [22], MWCNTs were ultrasonically dispersed in a liquid polysilazane precursor polymer, with subsequent casting, pressure-less cross-linking and thermolysis at $1000^{\circ} \mathrm{C}$. Preliminary investigations of the fracture toughness of thus obtained composites using a thermal loading method revealed that the extent to which the incorporated nanotubes enhance the mechanical properties depends strongly on their structural characteristics, in particular their aspect ratio [23]. Recently, we have utilized single-wall carbon nanotubes (SWCNTs) for the reinforcement of Si-C-N polymer-derived ceramics, and found that the increase of Young's modulus increases with the dispersion degree of the nanotubes inside the amorphous matrix [24]. However, while it is well-documented that the incorporation of SWCNTs into polymerderived amorphous ceramics can enhance their mechanical performance and electrical conductivity, detailed studies of the fracture toughness are very limited. Recent results reveal that the incorporation of MWCNT into Si-C-N amorphous ceramics and the formation of CNT - matrix interfaces lead to $25 \%$ increase of the fracture toughness [23]. Due to their small diameter SWCNT's basically provide a means to increase the interface area without changing carbon nanotubes weight fraction. A promising route toward well-separated and homogeneously distributed SWCNTs relies upon appropriate chemical functionalization of the tubes [25]. The work of Gojny et al.[26] has demonstrated that the presence of carboxylic groups on the surface leads to a better dispersion of the nanotubes in an epoxy system. Especially attractive is the use of polymers in the nanotube functionalization. In this context, Hill et al. have attached a polystyrene copolymer to SWCNTs, which then could be homogeneously dispersed within a polystyrene matrix [27].

Here, we report the synthesis of a polymer-derived Si-C-N amorphous ceramic, reinforced by octadecylamine-functionalised SWCNTs. It is demonstrated that the presence of long alkyl 
chains on the tubes promotes the efficient disintegration of nanotube bundles into individual nanotubes, and their dispersion inside the polymer precursor matrix. The major aim of this study was to explore the influence of concentration and agglomeration state of the SWCNTs on the mechanical and electrical properties of the resulting composites. To this end, the hardness and Young's modulus of the composites were determined by nanoindentation technique, while the fracture toughness was determined by measuring the crack opening displacement (COD) of indentation cracks.

\section{Experimental}

\subsection{Materials and processing of composites}

The SWCNT-reinforced polymer-derived $\mathrm{Si}-\mathrm{C}-\mathrm{N}$ ceramics were prepared following the procedure illustrated in Figure 1. Commercial liquid poly(ureamethylvinyl)silazane (Ceraset, KION, USA) was used as starting precursor polymer. Octadecylamine-functionalised SWCNTs (P5-SWCNTs) were purchased from Carbon Solutions, Inc., USA, 60-70 wt\% SWCNT loading) and utilized without any further purification. 1, 2-Dichlorobenzene (Aldrich, 99.9\%) was used as a solvent. The synthesis was performed by a standard Schlenk technique under argon. In the first step, the required amount of P5-SWCNT was dispersed for $15 \mathrm{~min}$ in $1 \mathrm{ml}$ of 1,2-dichlorobenzene using an ultrasonic bath (SONOREX RK 52H, $140 \mathrm{~W}$, BANDELIN electronic). In order to obtain 0.5, 1 and $2 \mathrm{wt} \%$ P5-SWCNT content, the calculated amounts of degassed Ceraset were added to the solution of P5-SWCNT, and further sonicated by an ultrasonic probe (SONOPULS HD2200, 200W, BANDELIN electronic) for $60 \mathrm{~min}$ in an ice bath under argon atmosphere. Subsequently, the solvent was removed under vacuum, and the resulting viscous slurry of Ceraset and P5-SWCNTs placed in a Teflon mould, which was tightly closed by a metal die. The cross-linking was performed at $360{ }^{\circ} \mathrm{C}$ for $6 \mathrm{~h}$ in an electric furnace (Heraeus) under argon atmosphere. Finally, the samples 
were subjected to pyrolysis in a quartz tube at $1000^{\circ} \mathrm{C}$ for $1 \mathrm{~h}$ under argon, with a heating and cooling rate of $10^{\circ} \mathrm{C} / \mathrm{h}$ and $25^{\circ} \mathrm{C} / \mathrm{h}$, respectively. A monolithic ceramic reference sample was prepared from pure Ceraset following the same procedure as described above.

\section{(Figure 1)}

\subsection{Morphology}

The samples were characterized using a Zeiss GEMINI LEO 1530 VP scanning electron microscope with an acceleration voltage of $3 \mathrm{kV}$ and working distance of $6 \mathrm{~mm}$. For this purpose, the samples were coated by a nominally $0.5 \mathrm{~nm}$ thick Pt-Pd layer.

\subsection{Mechanical testing}

Toward mechanical testing by nanoindentation, a special sample preparation technique [10] was employed. Specifically, plates of $2 \mathrm{~mm}$ width and $8 \mathrm{~mm}$ length were cut from the circular shaped samples with a diameter of $12 \mathrm{~mm}$, and then mounted into an alumina frame. The platelets were oriented with their side-face upwards, such that a width corresponding to the sample thickness became available for indentation (see inset of Figure 2a). In the last step, the sample surface was polished to a final roughness of $1 / 4 \mu \mathrm{m}$. Vickers indentation of samples was performed with a Buehler Micromet 1 micro indenter (Buehler LTD, Lake Bluff, IL, USA) with an applied load of $1 \mathrm{~kg}$. A representative indentation impression with welldeveloped radial cracks is shown in Figure 2a.

\section{(Figure 2)}

Crack profiles were determined with the aid of a scanning electron microscope (Gemini, Zeiss, Germany). The samples were first sputtered with a $0.8 \mathrm{~nm}$ thick layer of a gold/palladium alloy. To ensure high reproducibility, in all micrographs the border line between the inner dark region and the white edge region was defined as crack edge position. This was necessary since the edges of the crack faces are not perfectly defined due to deposited carbon contaminations and the sputtered metal. The crack opening along the crack tip was detected by an image assembling procedure (Figure $2 b$ ). In order to remain in the region displaying a 
parabolic shape of the crack opening displacement (COD) function, data have been collected for the first $5 \mu \mathrm{m}$ distance from the crack tip. A typical crack opening profile of the crack tip, together with a fitting line obtained using equation 2, is presented in Figure 2c. The plot shows a very good agreement between the fit and the measured data.

The nanoindentation experiments were performed in continuous stiffness mode (CSM) with a Nano Indenter XP nanoindentation system (MTS Nano Instruments, Oak Ridge, TN, USA) and a Berkovich indenter. Since a maximum load of $700 \mathrm{mN}$ is available for this instrument, the penetration depth was limited to $1.6 \mu \mathrm{m}$. Nevertheless, the volume of the plastic and elastic deformation field, formed by Berkovich indenter at this penetration depth, is big enough to ensure reliable results [28], as confirmed by reaching plateaus of the measured values already at the penetration depth of $800 \mathrm{~nm}$ (Figure 3). For each sample, the results were averaged over 60 measurements made at 5 different locations. At each location, a 4 x 3 array of indentations with a distance of $30 \mu \mathrm{m}$ was created. Hardness and Young's modulus were determined using the Oliver and Pharr analysis [29]. To this end, the Poisson's ratio value of 0.22 , as obtained for pure $\mathrm{SiCN}$ pyrolized at $1000^{\circ} \mathrm{C}$ [30], was used. Typical values of hardness and Young's modulus obtained in this manner are plotted as a function of tip displacement in Figure 3. In general, nanoindentation data obtained at small penetration depth are influenced by the surface roughness of the sample. Since the samples were polished to a final roughness of $1 / 4 \mu \mathrm{m}$, this influence can be recognized for penetration depths up to $300 \mathrm{~nm}$. Above this range, for both properties there occurs a slight increase, followed by a plateau above $800 \mathrm{~nm}$. The plateau values are expected to be most reliable.

\section{(Figure 3)}

\subsection{Electrical conductivity}

Electrical conductivity measurements were performed under ambient with a Keithley 2400 source-meter and a DLPCA-200 Femto amplifier. Contact to the samples was made by two needles and silver paste. As four - terminal measurments revealed the presence of only 
negligible contact resistance mainly 2-probe measurements were performed. All I/V curves acquired in the latter configuration generally showed ohmic behaviour.

\section{Results and discussion}

Microstructures at the crack faces for 1 wt $\%$ P-SWCNT/ Si-C-N nanocomposites show homogenously distributed carbon nanotubes and plenty of bridging structures reinforcing the enhancement of the mechanical properties (Figure 4).

\section{(Figure 4)}

SEM micrographs of the fracture surface of the P5-SWCNT-reinforced Si-C-N nanocomposites display a homogeneous distribution of the nanotubes for all three tube contents, as exemplified in Figure 5. This finding proves the capability of the appended alkyl chains to enhance the interaction with the polymer precursor matrix, which represents a useful extension of previous work on nanocomposites wherein carbon nanotubes are embedded in a polymer-derived ceramic matrix, as has been documented for pristine SWCNTs [24] or MWCNTs [22].

\section{(Figure 5)}

Besides the homogeneous distribution of the nanotubes, the SEM images reveal a similar fracture morphology for both 0.5 and $1 \mathrm{wt} \%$ of P5-SWCNs (Figure 5a and b), predominately consisting of tubes pulled out from the matrix. In contrast, less pull-out and more broken tubes can be observed for the sample reinforced by 2 wt \% (see Figure 5c). The different fracture surface morphologies can be explained by an increase of the precursor polymer viscosity due to the addition of the tubes, reflecting in higher carbon nanotube interactions and possibility of their agglomeration. Moreover, owing to the shrinkage of the matrix during pyrolysis, at higher nanotube concentrations the tubes are more densely packed, and hence their pull-out more difficult to detect. 
Another possible reason for the different fracture surface morphologies relates to the different interfacial strength of tubes and matrix. For fibre-reinforced composites, it is known that the ease of pulling out of fibres from the matrix or their breakage during fracture strongly depends on the interfacial strength of fibres and matrix [31]. Hence, crack deflection along the nanotubes and their subsequent pull-out will be more difficult, with the consequence that the tubes rather break. This explanation gains support from the fracture surface of all three nanocomposites (Figure 5).In addition, the length and diameter of the fibres, as well as their intrinsic strength and stiffness can have an influence, although these factors are not relevant in our experiments using the same type of tubes. In general, pulling-out of the tubes will be prominent when the tube strength exceeds the interfacial strength, while otherwise they will preferably break.

The values of hardness and Young's modulus, as derived from the nanoindentation loaddisplacement curves, are plotted in Figure 6 as a function of the P5-SWCNT content. For the pure polymer-derived Si-C-N ceramic, a Young's modulus of $\sim 141 \mathrm{GPa}$ and a hardness of 17.4 GPa are obtained (see Figure 6). These values agree well with those reported for polymer-derived Si-C-N ceramics prepared in the same way [23, 24]. It can be seen that the incorporation of nanotubes improves both properties in comparison to the pure polymerderived Si-C-N ceramic. Maximum enhancement is achieved for $2 \mathrm{wt} \%$ tube content, with a value of $182 \pm 2$ for Young's modulus and $20 \pm 0.4 \mathrm{GPa}$ for the hardness. The modulus increase by $\sim 30 \%$ is comparable to that observed for the SWCNT reinforcement of polymer derived-ceramic prepared in the same way [24]. By comparison, the observed hardness by $15 \%$ is higher than for the latter material [24].

\section{(Figure 6)}

The enhanced Young's modulus of the reinforced polymer-derived Si-C-N ceramic reflects a sizeable interfacial bonding strength between the ceramic matrix and the nanotubes, which is an important prerequisite for taking benefit of the exceptionally high Young's modulus of the 
nanotubes. Such bonding can also be concluded from TEM images of the interface between pristine SWCNTs and polymer-derived ceramics, which reveal good wetting of the ceramic by the tubes, but lack evidence of a strong coupling between these two materials [32]. Therefore, we suppose that chemical bonding between the precursor polymer and nanotubes via functional groups are not present. The octadecylamine modified SWCNT`s are soluble in common organic solvents that are compatible with polysilazane, making it possible to prepare those composites by solution-based method. It is furthermore documented that the integrity of the tubes is preserved during pyrolysis at $1000{ }^{\circ} \mathrm{C}[22,32]$. An additional contribution to the enhancement arises from the homogenous distribution of the tubes in the matrix (Figure 5), which ensures an efficient stress distribution from the matrix to the tubes. It is furthermore noteworthy that the purity of the present tubes is much higher than those in ref [24], which reduces the risk of mechanical failure associated with, e.g., amorphous carbon particles. This can explain the higher hardness of the present composites in comparison to previous studies [24].

Although a direct microscopic proof is lacking, it is nonetheless plausible that the present samples contain $\mathrm{SiC}$ nanocrystals at the nanotube/matrix interface, which could exert a positive influence on the properties. Indeed, TEM investigation [22] of Si-B-C-N/CNTs subjected to $1000{ }^{\circ} \mathrm{C}$ revealed the nanocrystalline character of the polymer-derived matrix in the vicinity of the tubes. Such template or nucleation effect of CNTs on the matrix crystallization has also been observed for polymer-based CNTs nanocomposites [33, 34]. In conclusion, the improved Young's modulus and hardness, as compared to polymer-derived ceramic reinforced by MWCNTs ( 120 GPa and $\sim 14 \mathrm{GPa}$ respectively) [21], underline the suitability of the alkyl-functionalized SWCNTs for enhancing the mechanical resilience of these ceramics.

The fracture toughness of the samples was determined through measurement of the crack opening displacement (COD) of indentation cracks in the crack tip vicinity $[35,36]$. As a 
major advantage in comparison to the standard crack length measurements [37], this method can be applied to materials showing any type of indentation behaviour [10, 38]. In fact, the validity of fracture toughness estimation of $\mathrm{CNTs} /$ ceramic matrix composites by measuring the crack length using indentation technique has been questioned [39]. By contrast, the COD approach relies upon the crack profile for constant applied load under Mode I conditions, and exploits the fact that the applied stress intensity $\left(\mathrm{K}_{\mathrm{A}}\right)$ is transferred to the stress field at the crack tip $\left(\mathrm{K}_{\mathrm{tip}}\right)$, while the near-tip half crack opening $(\mathrm{u})$ shows a parabolic dependence on the distance (x) from the crack tip:

$$
u(x)=\frac{K_{t i p}}{E} \sqrt{\frac{8 x}{\pi}}
$$

In this equation, $\mathrm{K}_{\text {tip }}$ is the stress intensity factor at the crack tip, and $\mathrm{E}$ is the Young's modulus for plain strain. The $\mathrm{K}_{\text {tip }}$ value can be obtained by fitting a parabolic profile to the measured crack tip COD as a function of the distance from the crack tip. This approach had originally been developed for compact tension (CT) specimens [35]. When applying it to determine $\mathrm{K}_{\mathrm{tip}}$ from indentation, however, a complication arises because only a small part of the COD profile close to the crack tip is of parabolic shape [36]. At larger distance from the tip, due to the high residual stress originating from the region near the indent, the parabolic shape can be severely distorted. In order to account for this deviation, a phenomenological fit for the data measured on indentation made cracks has been proposed and proven reliable [10]. The corresponding equation

$u(x)=\frac{K_{t i p}}{E} \sqrt{\frac{8 x}{\pi}}+A x^{\frac{3}{2}}+B x^{\frac{5}{2}}$

contains two fitting parameters A and B. Since the present fully dense polymer-derived ceramics reinforced by CNTs can be produced only as small (12 $\mathrm{mm}$ diameter) and thin samples (0.45 $\mathrm{mm}$ thickness), this fitting method is appropriate [10].

Thus obtained fracture toughness data of the nanocomposites are presented in Figure 7 as a function of CNT content. The value of $1.4 \pm 0.1 \mathrm{MPa} \mathrm{m}{ }^{1 / 2}$ obtained for pure polymer derived 
Si-C-N is included as $0 \mathrm{wt} \%$ sample. A more than 2-fold increase of fracture resistance is observed for all CNTS content in comparison to the pure polymer-derived ceramic.

\section{(Figure 7)}

All three major toughening mechanisms documented for ceramic matrix composites reinforced by micron-scale fibres [40], i.e., crack bridging by fibres, fibre pull-out on the fracture surfaces, and crack deflection at the fibre/matrix interface, are likely to contribute to the toughening in the present samples. Especially the crack deflection mechanism should be operative in light of the high aspect ratio of the used SWCNTs, which represents a critical factor governing the efficacy of crack deflection along the interface [22, 23]. Moreover, the tubes' high tensile strength and stiffness is expected to allow effective crack bridging (Figure $7 \mathrm{~b}$ and c) and their pull-out (cf. Figure 5). The relevance of these three mechanisms is further supported by the homogenous distribution of the tubes in the matrix (Figure 5), which may also explain the smaller fracture toughness of $1.8 \mathrm{MPa} \mathrm{m}^{1 / 2}$ obtained for polymer-derived SiC-N ceramics reinforced by $2 \mathrm{wt} \%$ of pristine SWCNTs [23]. It is furthermore noteworthy that the fracture toughness does not monotonously increase with rising SWCNT content, but rather displays a maximum of $\sim 3.1 \pm 0,2 \mathrm{MPa} \mathrm{m}^{1 / 2}$ at $1 \mathrm{wt} \%$, which is followed by a value of $\sim 2.6 \pm 0.2 \mathrm{MPa} \mathrm{m}^{1 / 2}$ at the content of $2 \mathrm{wt} \%$. This trend can be understood on the basis that with increasing content of the tubes, the stiffness and strength of the polymer-derived matrix likewise increases (Figure 6).

The room temperature electrical conductivity of the pure Si-C-N ceramic pyrolyzed at $1000^{\circ} \mathrm{C}$ was found to be $3.10^{-9} \mathrm{~S} / \mathrm{cm}$ demonstrating its close-to-insolating behavior. Upon incorporation of $0.5 \mathrm{wt} \%$ P5-SWCNTs, the conductivity after pyrolysis increased by five orders of magnitude to $10^{-4} \mathrm{~S} / \mathrm{cm}$. As apparent from Figure 8, the pyrolized specimen display a percolation threshold below $0.5 \mathrm{wt} \%$, and their conductivity reaches a saturation value of $\sim 0.1 \mathrm{~S} / \mathrm{cm}$ for a tube content of $2 \mathrm{wt} \%$. A similar trend has been reported for MWCNT/SiCN composites comprising well-dispersed, non-functionalized nanotubes of high aspect ratio, 
whereas values $>2 \%$ are often found in case of CNT/polymer composites [41]. Importantly, the low percolation threshold is not the result of phase segregation, but is rather attained through homogenous dispersion of the P5-SWCNTs within the polymer matrix (see Figure 5), which is also responsible for the enhanced fracture toughness.

\section{( Figure 8)}

\section{Conclusions}

In summary, polymer-derived $\mathrm{Si}-\mathrm{C}-\mathrm{N}$ ceramics have been reinforced by alkyl chainfunctionalized SWCNTs. We find a remarkably large, more then 2-fold, increase of fracture resistance in our composites. Furthermore, the incorporation of nanotubes increases the Young's modulus and hardness of the ceramic matrix by $30 \%$, i.e $15 \%$ (for $2 \mathrm{wt} \%$ ), respectively. At the same time, the electrical conductivity is strongly enhanced for tube contents as low as $0.5 \mathrm{wt} \%$. It is concluded that adequately functionalized SWCNTs are a promising filler material for polymer-derived ceramics, with the potential to obtain composites of high temperature stability as well as excellent toughness and creep resistance.

\section{Acknowledgements}

This work is supported within the scope of Schwerpunktprogramm SPP1181 by the Deutsche Forschungsgemeinschaft (DFG). 


\section{References}

[1] Bill J, Aldinger F. Precursor-derived Covalent Ceramics. Adv Mater 1995; 7: 775-87.

[2] Thurn G, Canel J, Bill J, Aldinger F. Compression creep behaviour of precursorderived Si-C-N Ceramics J Euro Ceram Soc 1999; 19: 2317-23.

[3] Peng JQ, Seifert HJ, Aldinger F. Thermal stability of precursor-derived Si-(B)-C-N ceramics. Ceramic Transaction 115, Proc. The American Ceramic Society’s 102nd Annual Meeting 2000; 251.

[4] Zimmermann A, Bauer A, Christ M, Cai Y, Aldinger F. High-temperature deformation of amorphous Si-C-N and Si-B-C-N ceramics derived from polymers Acta Mat 2002; 50: 1187-96.

[5] Janakiraman N, Aldinger F. Indentation analysis of elastic and plastic deformation of precursor-derived Si-C-N ceramics J Eur Ceram Soc 2010; 30: 775-85.

[6] Müller A., Peng JQ, Seifert HJ, Bill J, Aldinger F. Si-B-C-N ceramic precursors derived from dichlorodivinylsilane and chlorotrivinylsilane. 2. Ceramization of polymers and high- temperature behaviour of ceramic materials. Chem Mater 2002; 14: 3406-12.

[7] Hörz M, Zern A, Berger F, Haug J, Müller K, Aldinger F. Novel Polysilazanes as Precursors for Silicon Nitride/Silicon Carbide Composites without "Free" Carbon. J Eur Ceram Soc 2005; 25; 99-110.

[8] Bill J, Kamphowe TW, Mueller A, Wichmann T, Zern A, Jalowieki A, Mayer J, Weinmann M, Schuhmacher J, Mueller K, Peng J, Seifert HJ, Aldinger F. Precursor-derived Si-(B-)C-N ceramics: thermolysis, amorphous state and crystallization. Appl Organomet Chem 2001; 15: 777-93.

[9] Bauer A, Christ M, Zimmerman A, Aldinger F. Fracture toughness of amorphous precursor-derived ceramics in the silicon-carbon-nitrogen system. J Amer Ceram Soc 2001; 84: 2203-07.

[10] Burghard Z. PhD thesis University of Stuttgart, Stuttgart 2004. 
[11] Janakiraman N, Burghard Z, Aldinger F. Fracture toughness evaluation of precursorderived $\mathrm{Si}-\mathrm{C}-\mathrm{N}$ ceramics using the crack opening displacement approach. J Non-Crystall Sol 2009; 355: 2102-13.

[12] Padtur NP. Multifunctional Composites of Ceramics and Single-Walled Carbon Nanotubes. Adv Mater 2009; 21: 1767-70.

[13] Cho J, Boccaccini AR, Shaffer MSP. Ceramic matrix composites containing carbon nanotubes. J Mat Sci 2009; 44: 1934-51.

[14] Treacy MMJ, Ebbesen TW, Gibson JM. Exceptionally high Young's modulus observed for individual carbon nanotubes. Nature 1996; 381: 678-80.

[15] Wong EW, Sheehan PE, Lieber CM. Nanobeam Mechanics: Elasticity, Strength, and Toughness of Nanorods and Nanotubes. Science 1997; 277: 1971-74.

[16] Krishnan A, Dujardin E, Ebbesen TW, Yianilos PN, Treacy MMJ. Young's modulus of single-walled nanotubes. Phys Rev B 1998; 58; 14013-19.

[17] Yu MF, Files BS, Arepalli S, Ruoff RS. Tensile Loading of Ropes of Single Wall Carbon Nanotubes and their Mechanical Properties. Phys Rev Lett 2000; 4: 5552-55.

[18] Berber S, Kwon YK, Tomanek D. Unusually High Thermal Conductivity of Carbon Nanotubes. Phys Rev Lett 2000; 84: 4613-16.

[19] Anazawa K, Shimotani K, Manabe C, Wanatabe C, Shimizu M. High-purity carbon nanotubes synthesis method by an arc discharging in magnetic field. App Phys Lett 2002; 81: $739-41$

[20] Cho J, Boccaccini AR, Shaffer MSP. Ceramic matrix composites containing carbon nanotubes. J Mater Sci 2009; 44: 1934-51.

[21] An LN, Xu WX, Rajagopalan S, Wang CM, Wang H, Fan Y, Zhang LG, Jiang DP , Kapat J, Chow L, Guo BH, Liang J, Vaidyanathan R. Carbon-Nanotube-Reinforced PolymerDerived Ceramic Composites. Adv Mater 2004; 16: 2036-40.

[22] Katsuda Y, PhD thesis, University of Stuttgart, 2006. 
[23] Katsuda Y, Gerstel P, Narayanan J, Bill J, Aldinger F. Reinforcement of precursorderived Si-C-N ceramics with carbon nanotubes. J Amer Ceram Soc 2006; 26: 3399-05.

[24] Burghard Z, Schon D, Bill J, Aldinger F. Polymer-derived Si-C-N ceramics reinforced by single wall carbon nanotubes. Int J Mat Res 2006; 97: 1667-72.

[25] Li Y, Fernandez-Recio L, Gerstel P, Srot V,van Aken PA, Kaiser A, Burghard M, Bill J. Chemical Modification of Single-Walled Carbon Nanotubes for the Reinforcement of Precursor-Derived Ceramics. Chem Mater 2008; 20: 5593-99.

[26] Gojny FH, Nastalczyk J, Roslaniec Z, Schulte K. Surface modified carbon nanotubes in CNT/epoxy-composites. Chem Phys Lett 2003; 370: 820-24.

[27] Hill DE, Lin Y, Allard LF, Sun Y. Solubilisation of carbon nanotubes vie polymer attachment. Int J Nanosci 2002; 3-4: 213-21.

[28] Bhushan B, Li X. Nanomechanical characterisation of solid surfaces and thin films. Int Mater Rev 2003; 48: 125-64.

[29] Oliver WC, Pharr GM. An improved technique for determining hardness and elastic modulus using load and displacement sensing indentation experiments. J Mater Res 1992; 7: 1564-83.

[30] Janakiraman N., Aldinger F. Fabrication and characterization of fully dense Si-C-N ceramics from a poly(ureamethylvinyl)silazane precursor. J Eur Cer Soc 2009, 29: 163-173.

[31] Steen M, Valles JL. Interfacial Bond conditions and Stress Distribution in a 2-D

Reinforced Brittle Matrix Composite. Comp Sci Tech1998; 58: 313-30.

[32] Cai Y, Shah SR, Zimmermann A, Weinmann M, Raj R, Aldinger F. Carbon Nanotubes Welded by Precursor Derived Silicoboron Carbonitride Ceramics. Phys Stat Sol A 2002; 193: R13-15.

[33] Valentinia L, Biagiottia J, Kenny JM, Santucci S. Morphological characterization of single-walled carbon nanotubes-PP composites. Com Sci Techn 2003; 63: 1149-53. 
[34] Probst O, Moore EM, Resasco DE, Grady BP. Nucleation of Polyvinyl Alcohol

Crystallization by Single-walled Carbon Nanotubes. Polymer 2004; 45: 4437-43.

[35] Rödel J, Kelly JF, Lawn BR. In situ Measurements of Bridged Crack Interfaces in the SEM. J Am Ceram Soc 1990; 72: 3313-18.

[36] Seidel J, Rödel J. Measurement of Crack Tip Toughness in Alumina as a Function of Grain Size. J Am Ceram Soc 1997; 80: 433-38.

[37] Anstis GR, Chanticul P, Lawn BR, Marshall DB. A Critical Evaluation of Indentation Techniques for Measuring Fracture Toughness: I, Direct Crack Measurements. J Amer Ceram Soc 1981; 64: 533-38.

[38] Burghrad Z, Zimmerman A, Aldinger F, Rödel J, Lawn BR. Crack opening profiles of indentation cracks in normal and anomalous glasses. Acta Mat 2004; 52: 293-97.

[39] Sheldon BW, Curtin WA. Nanoceramic Composites: Tough to Test. Nat Mat 2004; 3: 505-6.

[40] Curtin WA. Dimensionality and Size Effects on the Strength of Fiber-Reinforced Composites. Comp Sci Tech 2000, 60, 543-51.

[41] Ionescu E, Francis A, Riedel R. Dispersion assessment and studies on AC percolative conductivity in polymer-derived Si-C-N/CNT ceramic nanocomposites. J Mater Sci 2009; 44: 2055-62. 


\section{Figure captions}

Figure 1. Synthesis scheme of polymer derived (Si-C-N) ceramics reinforced by octadecylamine-modified SWCNT.

Figure 2. a) SEM micrographs of the Vickers indentation impression with associated radial crack system in Si-C-N nanocomposite reinforced by 1 wt \% P5-SWCNTs, the inset on the right represents picture of the sample mounted in the alumina holder b) crack tip geometry displayed by an appropriately arranged set of individual SEM images c) crack opening displacement $\mathrm{u}(\mathrm{x})$ from the crack tip, data fit (line) is obtained with Equation 2.

Figure 3. Plots of a) hardness and b) Young's modulus derived via nanoindentation for the polymer-derived Si-C-N nanocomposite reinforced with 2 wt \% P5-SWCNs as a function of penetration depth.

Figure 4. SEM micrographs at the crack face of the $1 \mathrm{wt} \% \mathrm{P}-\mathrm{SWCNT} / \mathrm{Si}-\mathrm{C}-\mathrm{N}$ nanocomposites.

Figure 5. SEM micrographs of the fracture surfaces of polymer-derived Si-C-N nanocomposite reinforced with a) $0.5 \mathrm{wt} \%$, b) $1 \mathrm{wt} \%$ and c) $2 \mathrm{wt} \%$ P5-SWCNs.

Figure 6. Dependence of Young's modulus (a) and hardness (b), derived from nanoindentation data of P-SWCNT /polymer-derived Si-C-N ceramic samples with different nanotube content.

Figure 7 a) Dependence fracture toughness extracted from COD data of P-SWCNT/polymer derived Si-C-N ceramics, on nanotube content; b) and c) examples of crack bridging by CNTs at different distance from the crack tip.

Figure 8. Dependence of the electrical conductivity of P-SWCNT/Si-C-N ceramic composites on the nanotube content. 

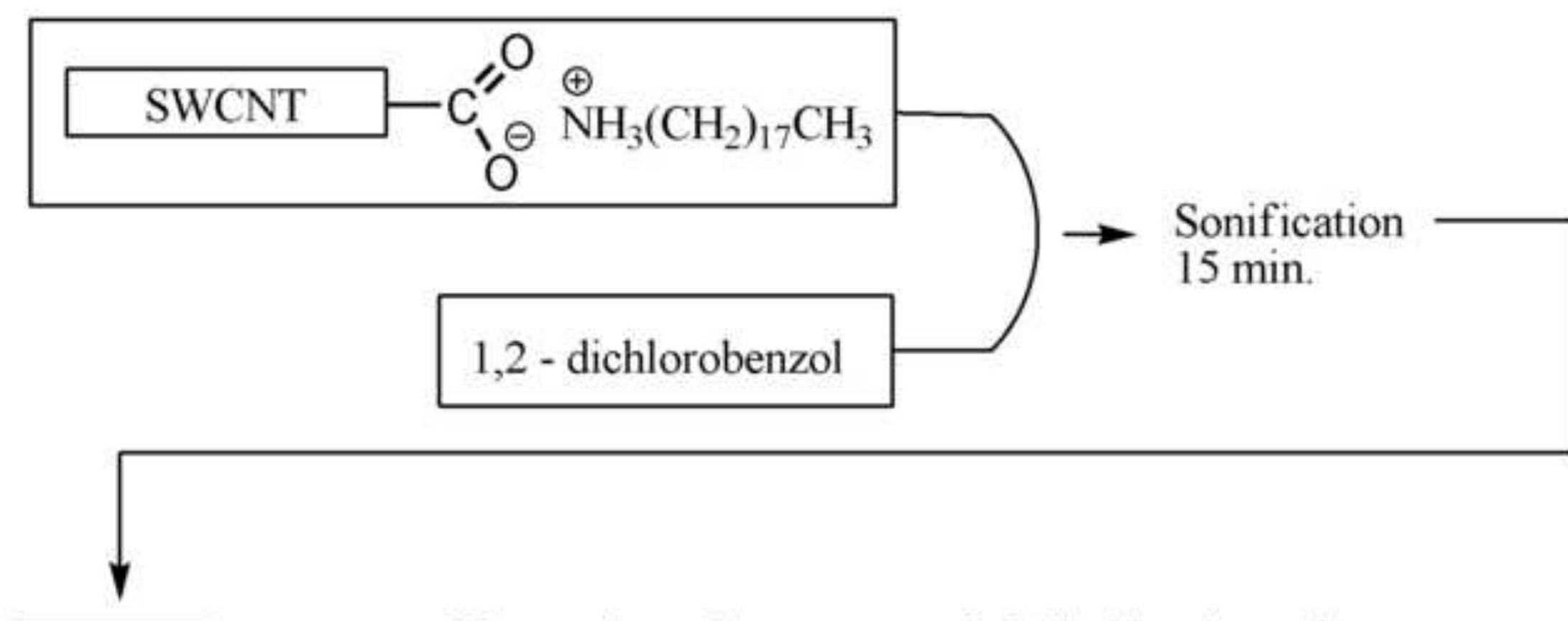

Ceraset

Ultrasonic probe $60 \mathrm{~min}$., Ar

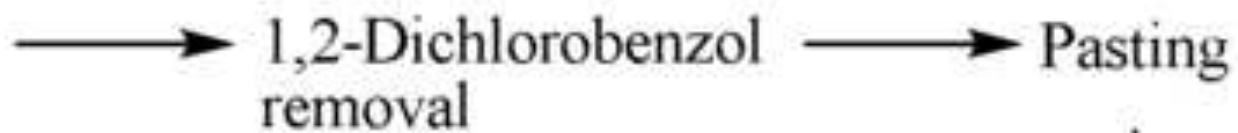

$$
\downarrow
$$

Cross-linking 6 h, $\mathrm{Ar}, 360^{\circ} \mathrm{C}$

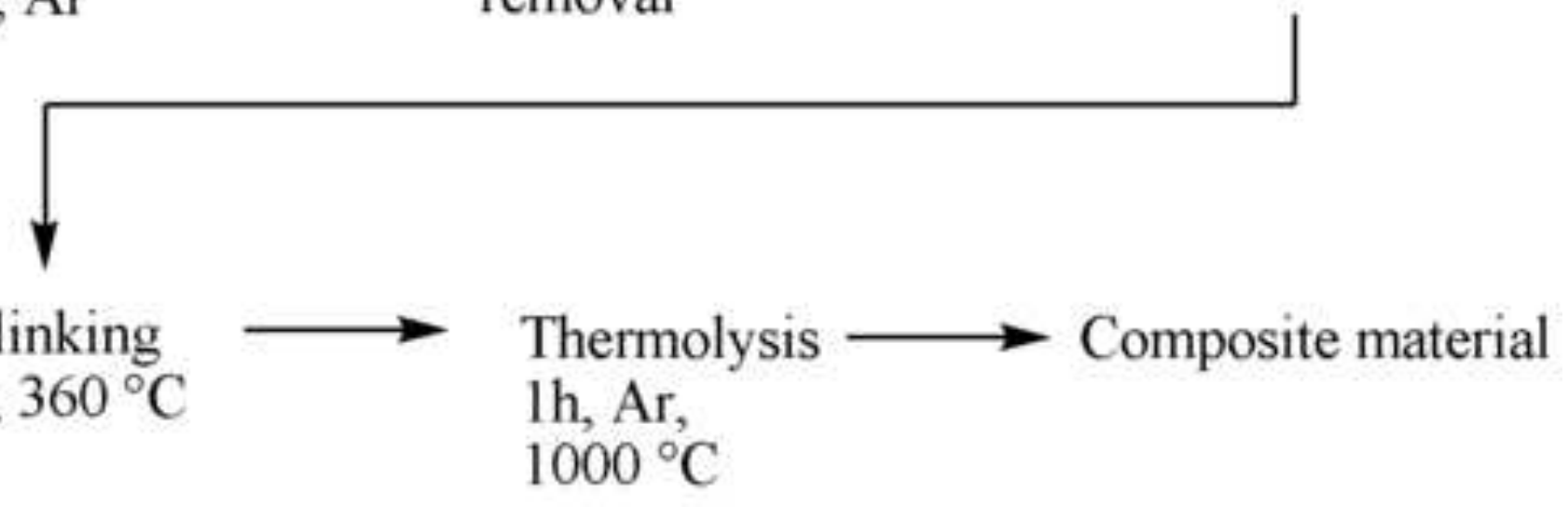

$\longrightarrow$ Composite material $1000^{\circ} \mathrm{C}$ 

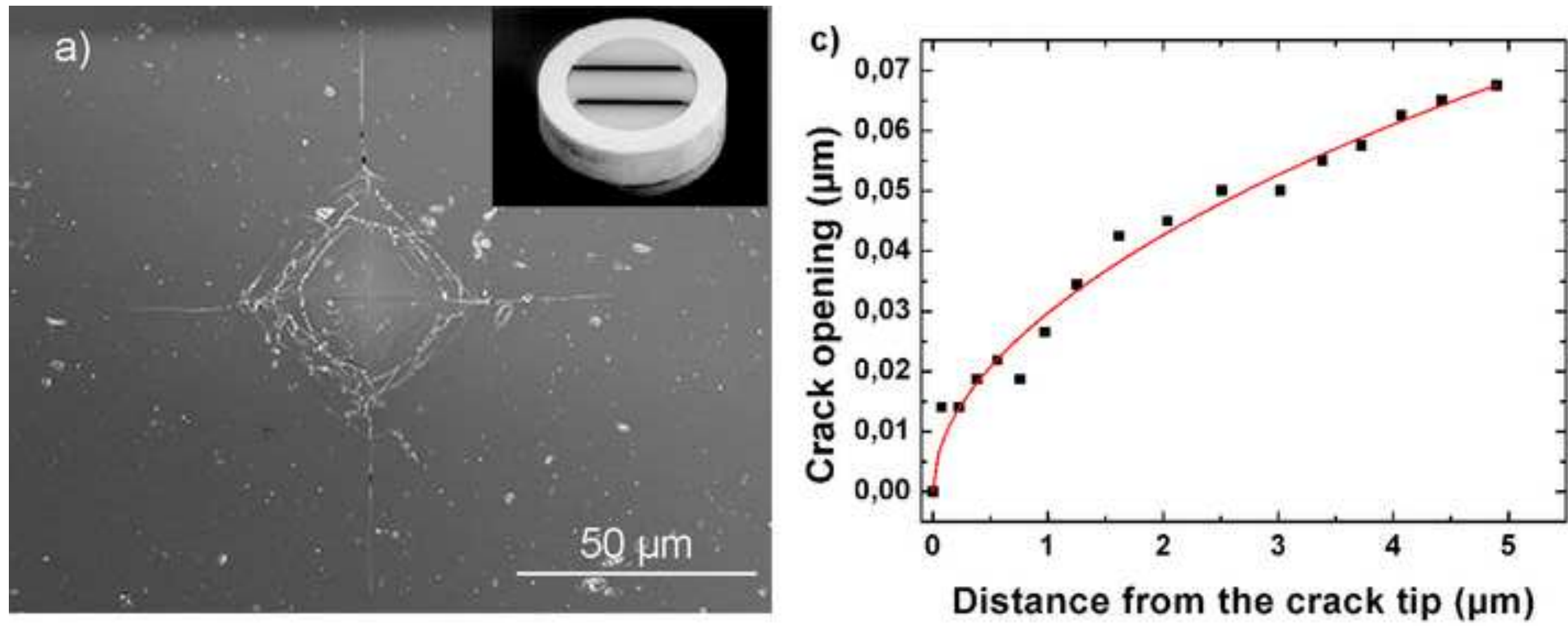

b) 


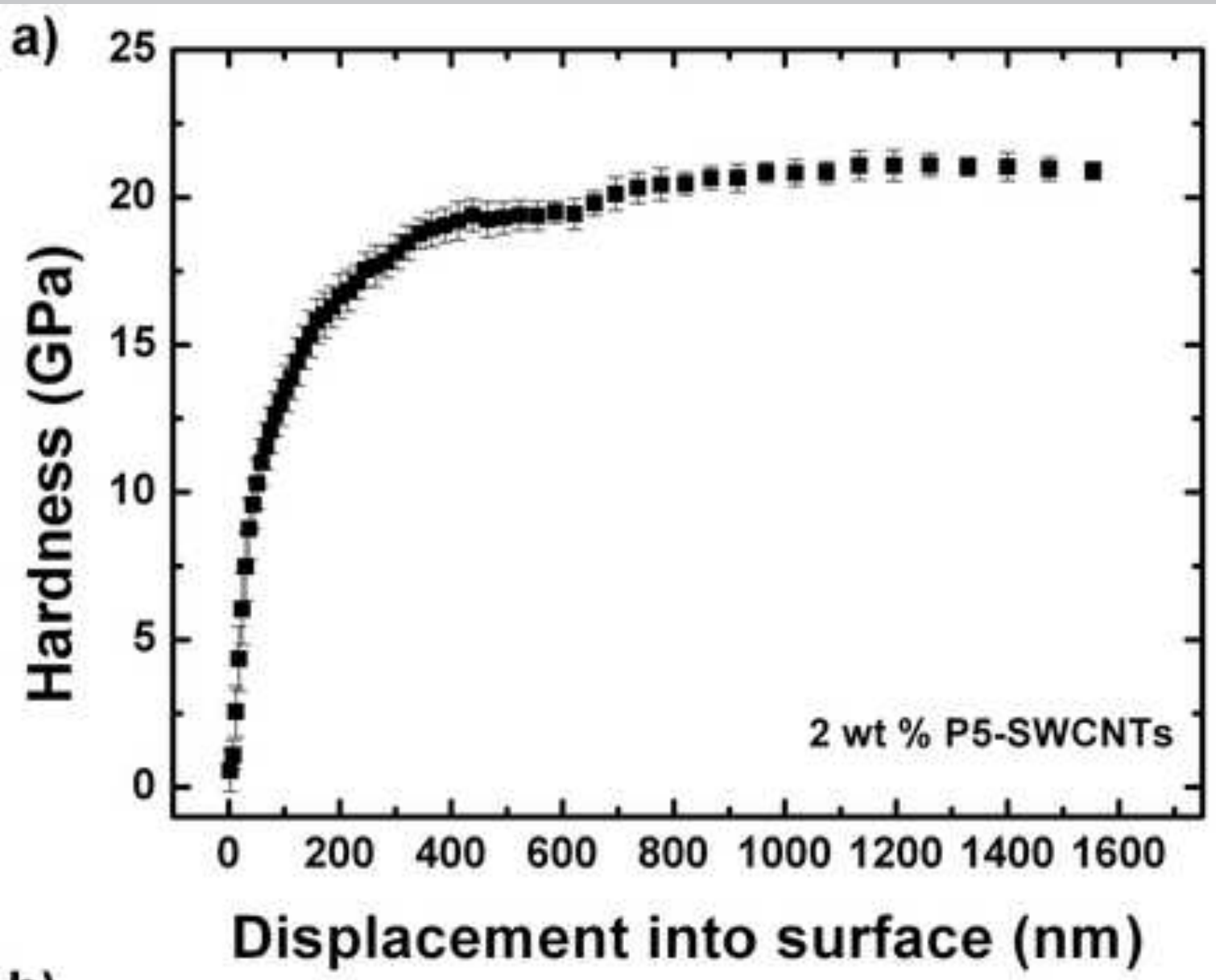

b)

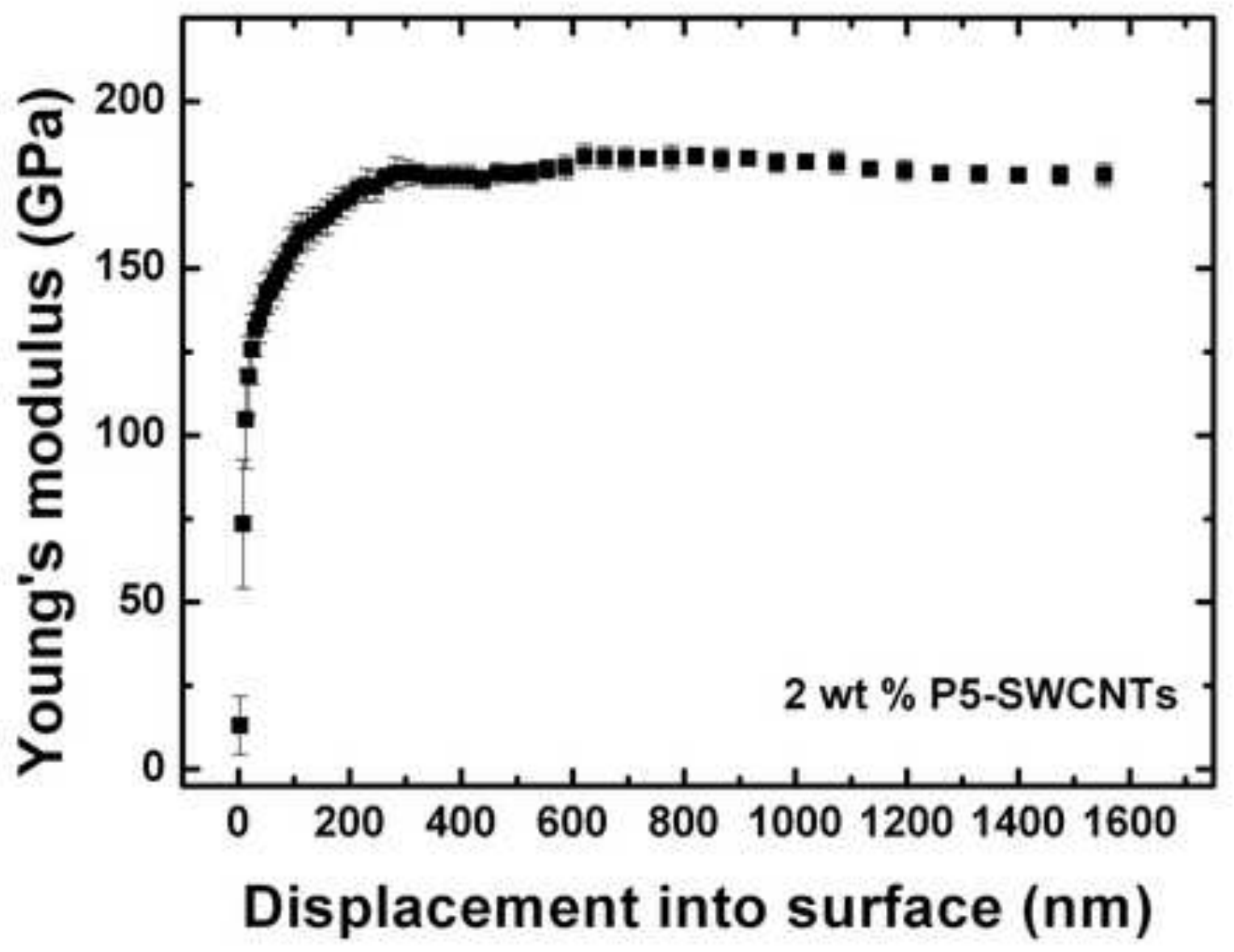




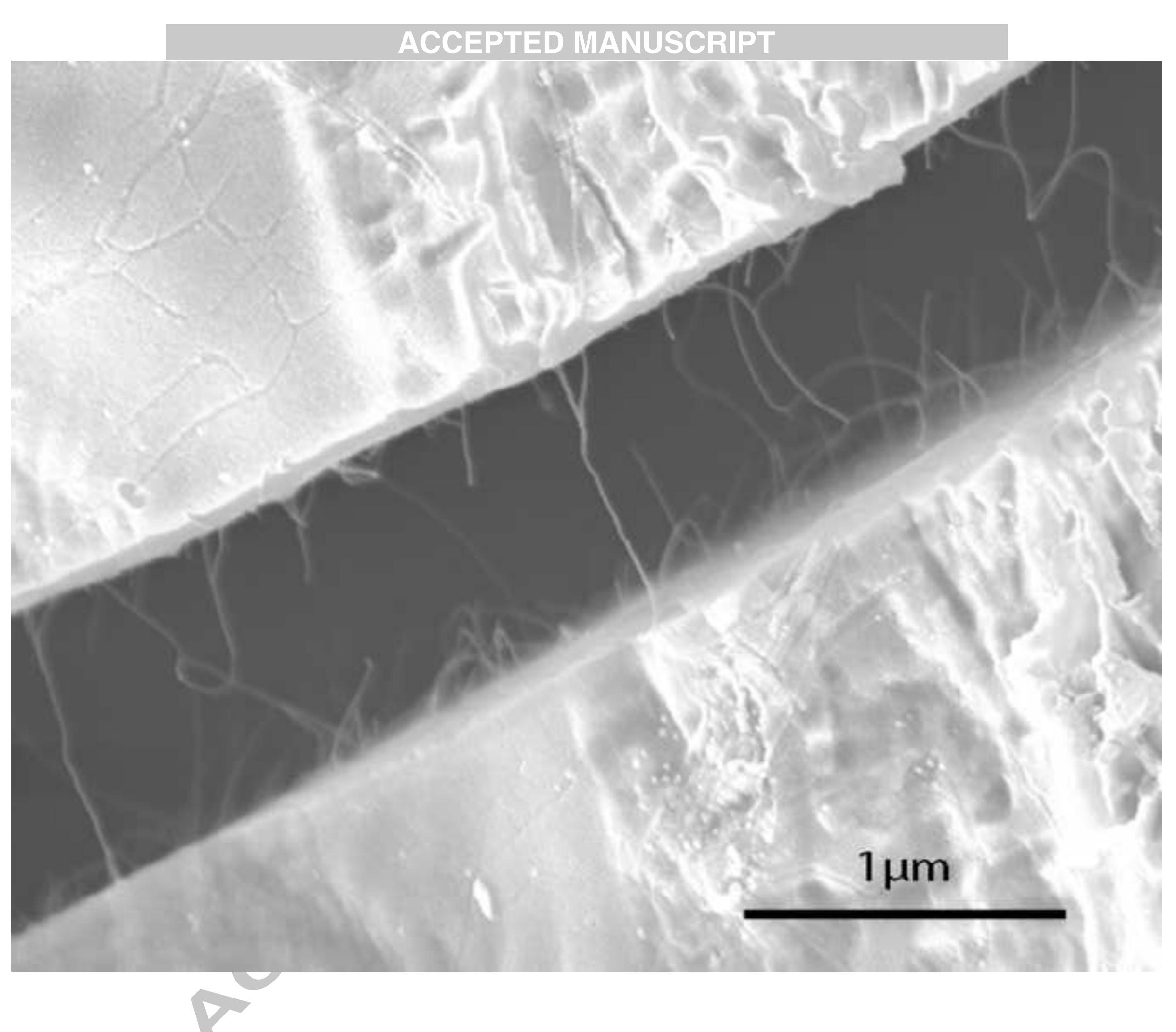

Figure
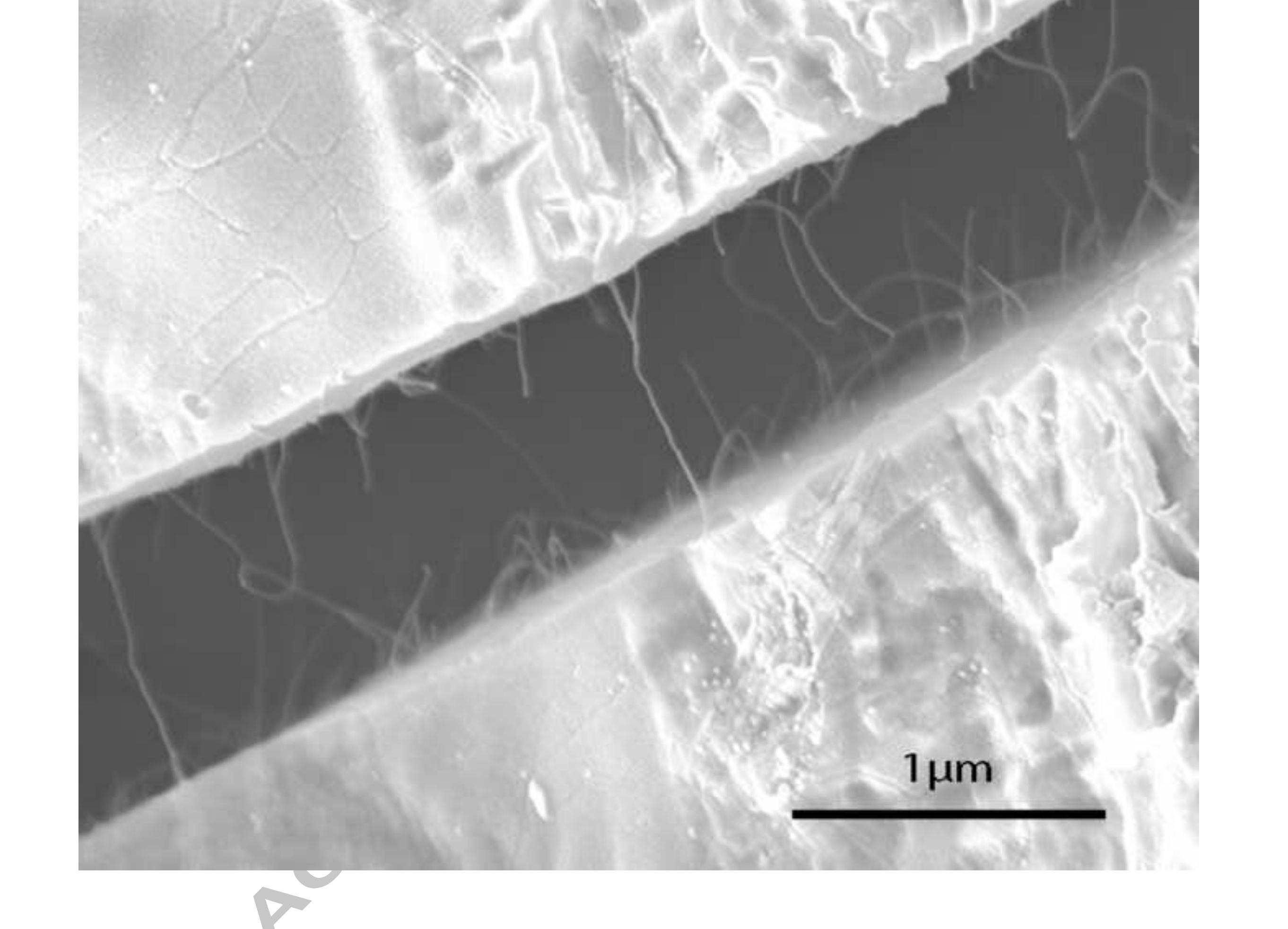


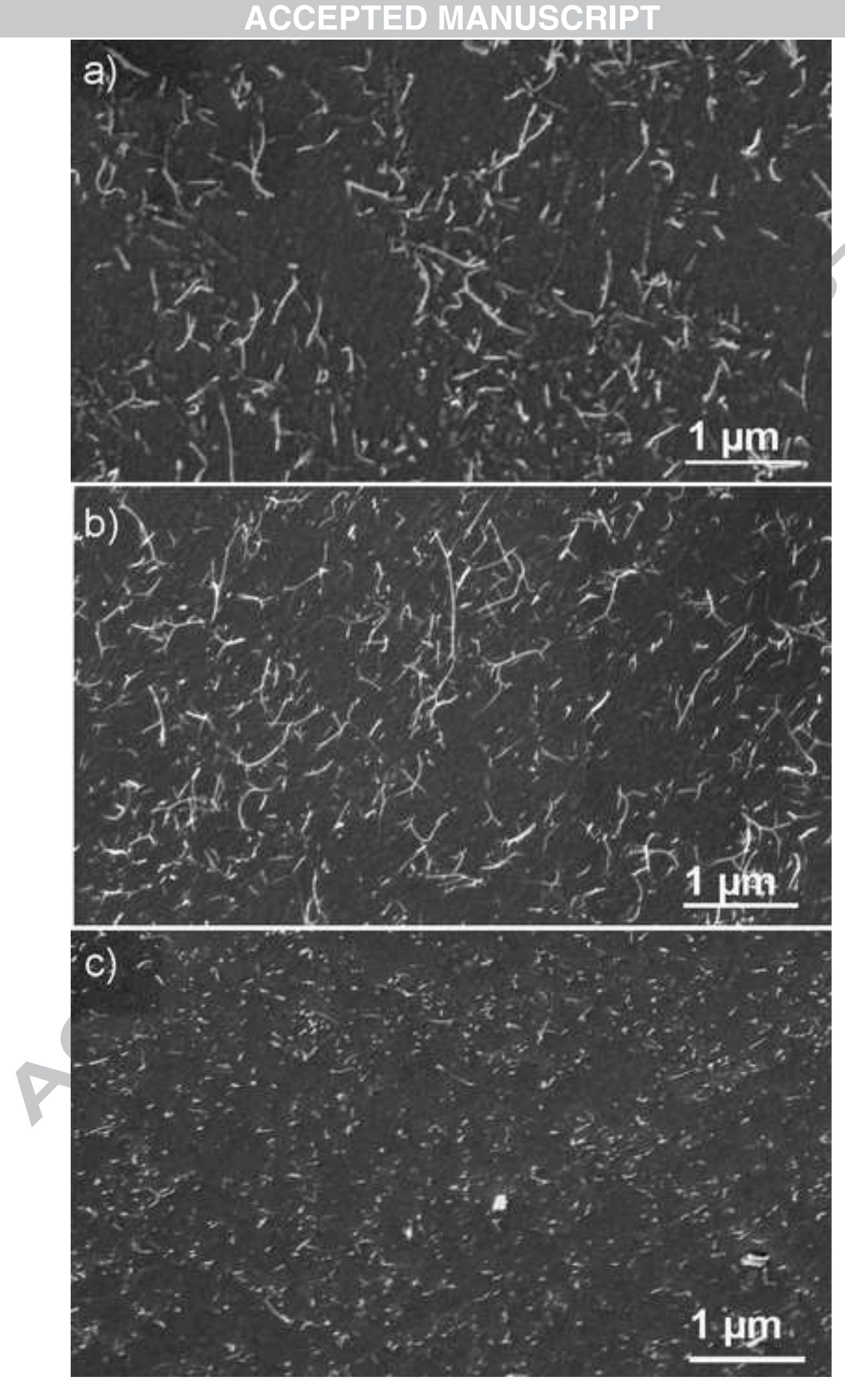


ACCEPTED MANUSCRIPT
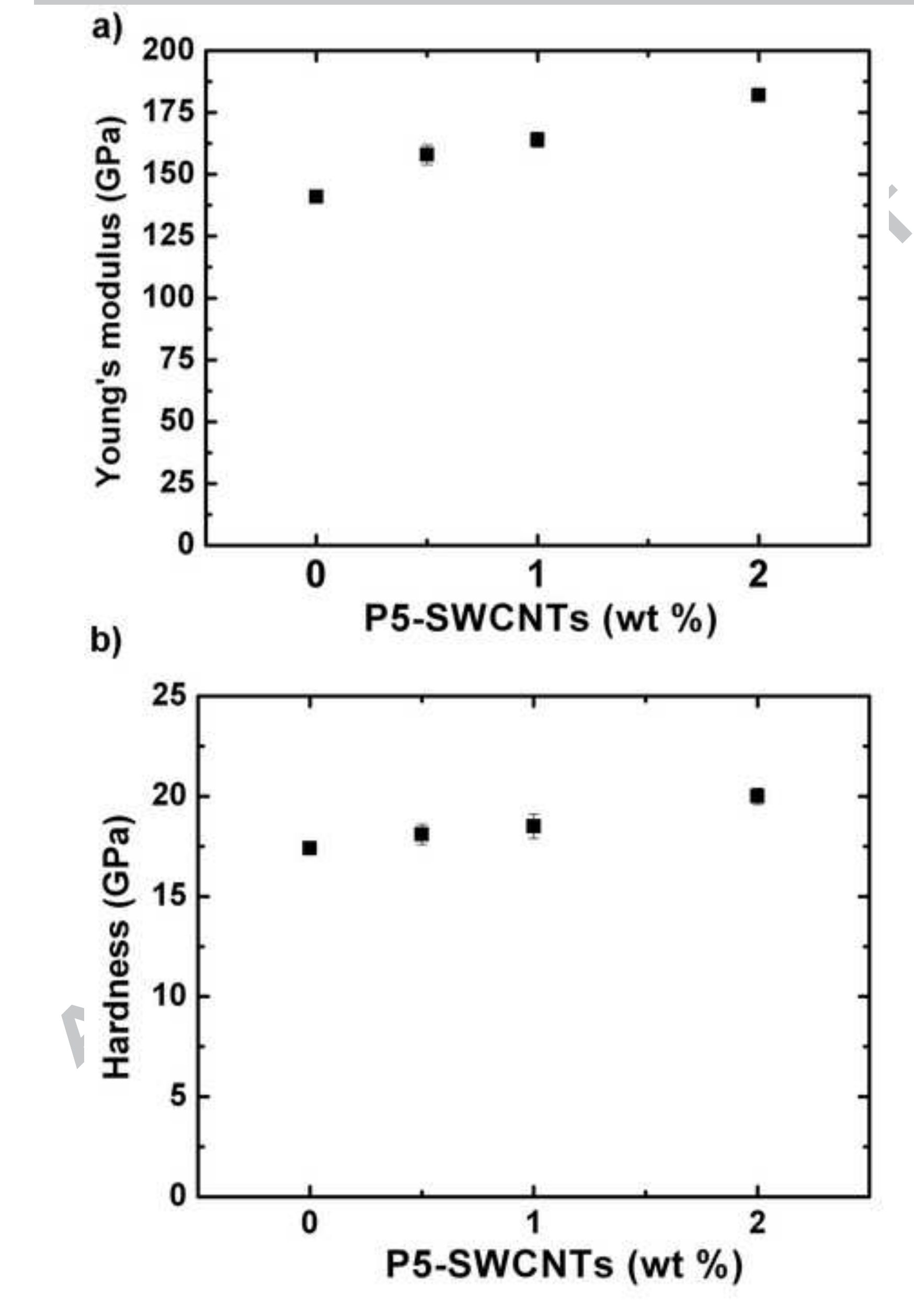

Figure6

a)
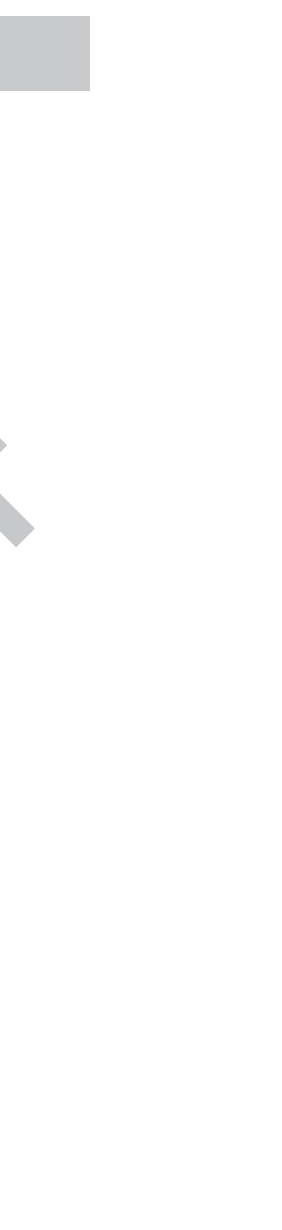

Figre6 
a)

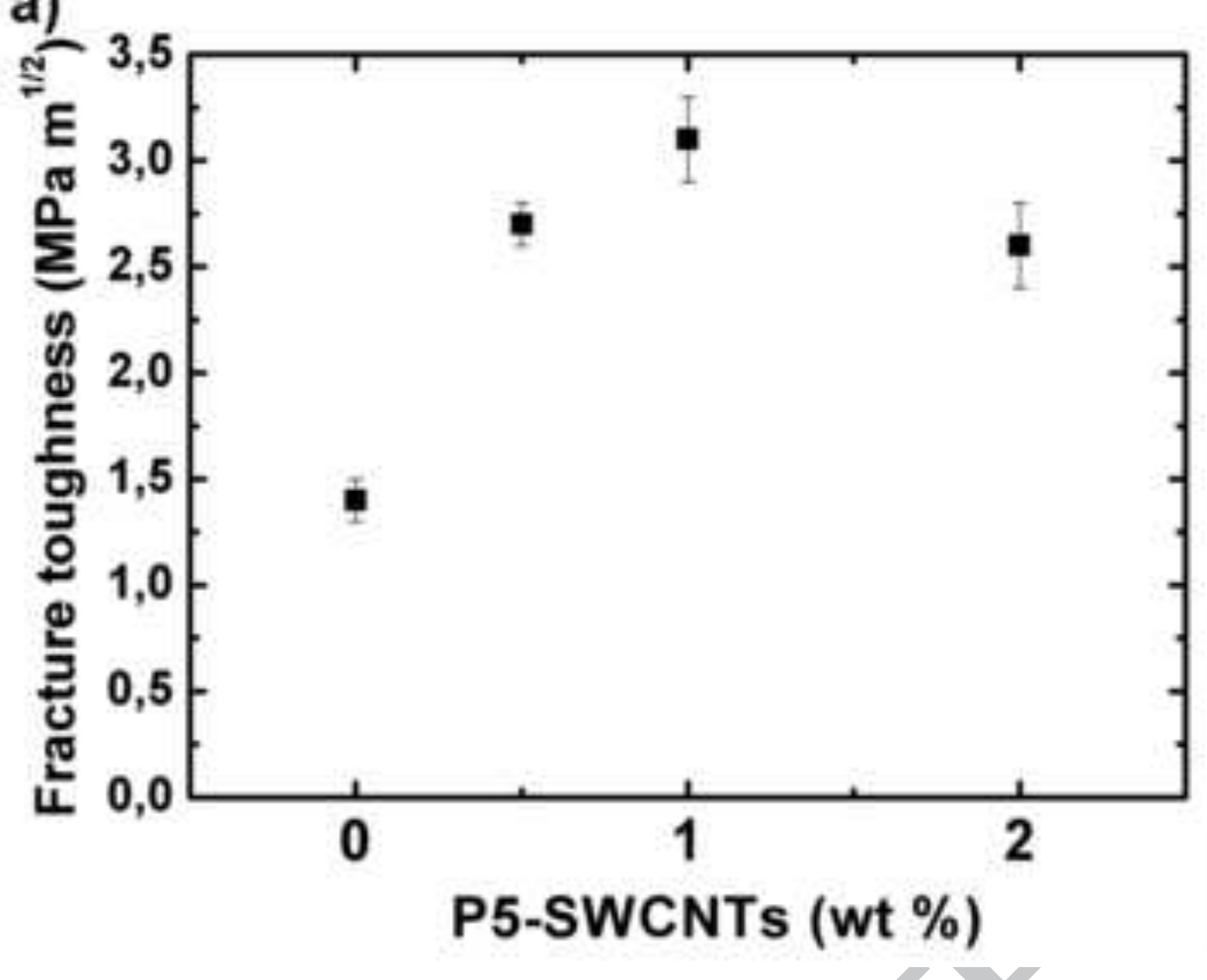

b)

$250 \mathrm{~nm}$

c)

$500 \mathrm{~nm}$

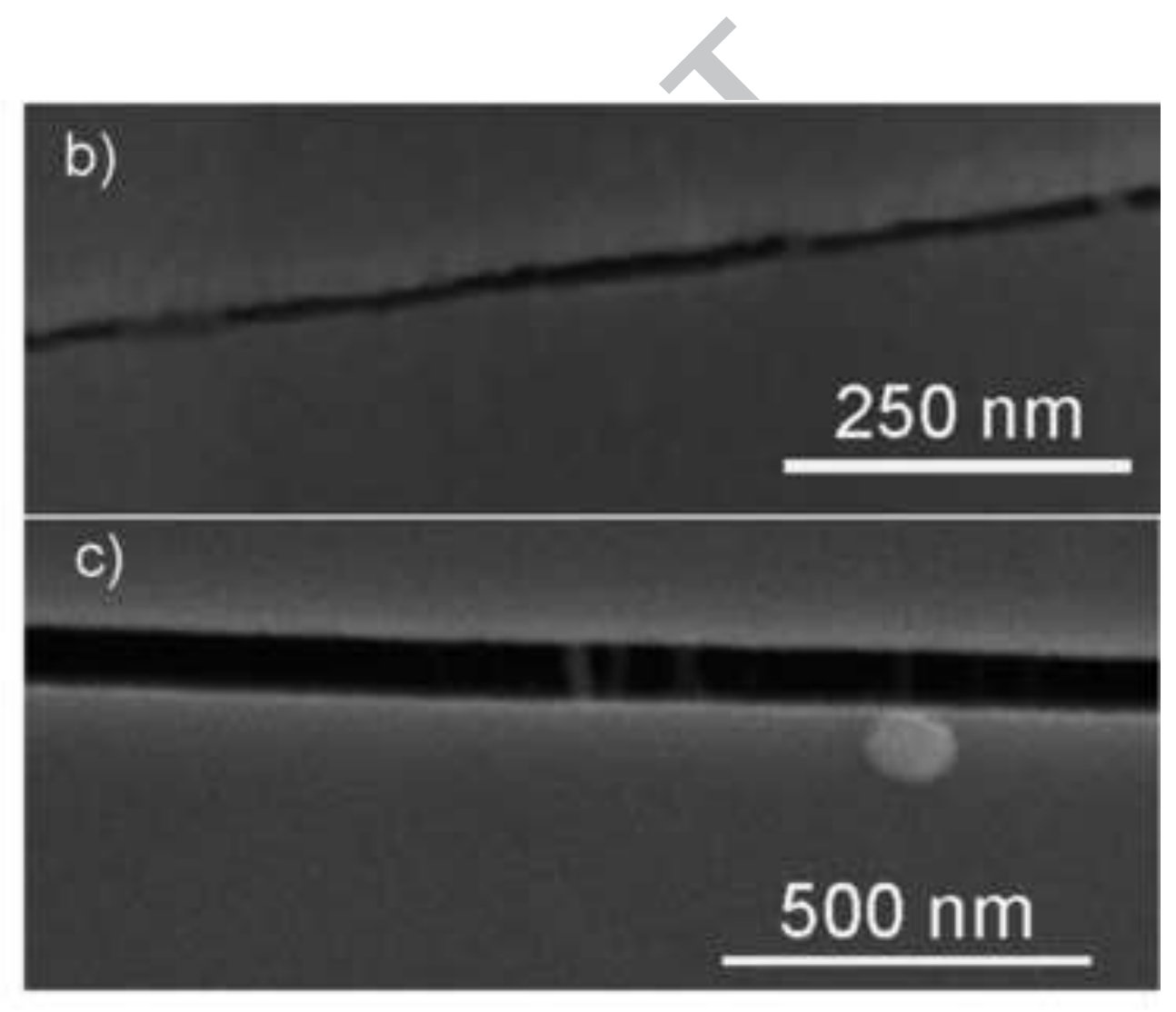


